\title{
Commentary to: Metabolic engineering of Escherichia coli: construction of an efficient biocatalyst for D-mannitol formation in a whole-cell biotransformation
}

\author{
B. Kaup $^{1} \cdot$ S. Bringer-Meyer ${ }^{1} \cdot$ H. Sahm ${ }^{1}$
}

Published online: 19 December 2015

(C) Springer-Verlag Berlin Heidelberg 2015

Commentary to: Appl Microbiol Biotechnol (2004) 64: 333-339

DOI 10.1007/s00253-003-1470-9

Notice of duplicate publication:

The data of 'Metabolic engineering of Escherichia coli: construction of an efficient biocatalyst for D-mannitol formation in a whole-cell biotransformation. Authored by Kaup B, Bringer-Meyer S, Sahm H, Appl Microbiol Biotechnol (2004) 64: 333-339 DOI 10.1007/s00253-003-1470-9' has been published previously in the following conference proceedings: 'Metabolic engineering of Escherichia coli: construction of an efficient biocatalyst for D-mannitol formation in a whole-cell biotransformation. Authored by Kaup B, BringerMeyer S, Sahm H. Commun Agric Appl Biol Sci. 2003;68(2 Pt A):235-40. It was decided to publish this notice to inform readers. This dual publication was unintentional. The proceedings paper, based on a workshop, formed the further basis for the journal article.

The online version of the original article can be found at http://dx.doi.org/ $10.1007 / \mathrm{s} 00253-003-1470-9$.

\footnotetext{
S. Bringer-Meyer

st.bringer-meyer@fz-juelich.de

Institut für Biotechnologie 1, Forschungszentrum Jülich GmbH,

52425 Jülich, Germany
} 